University of the Pacific Scholarly Commons

$5-1-2004$

\title{
Gastrabulary: A Future Terminology of Eating
}

Ken Albala

University of the Pacific, kalbala@pacific.edu

Lisa Cooperman

Follow this and additional works at: https://scholarlycommons.pacific.edu/cop-facarticles

Part of the Food Security Commons, History Commons, and the Sociology Commons

\section{Recommended Citation}

Albala, K., \& Cooperman, L. (2004). Gastrabulary: A Future Terminology of Eating. Gastronomica, 4(2), 110. DOI: 10.1525/ gfc.2004.4.2.110

https://scholarlycommons.pacific.edu/cop-facarticles/33 


\section{A Future Terminology of Eating}

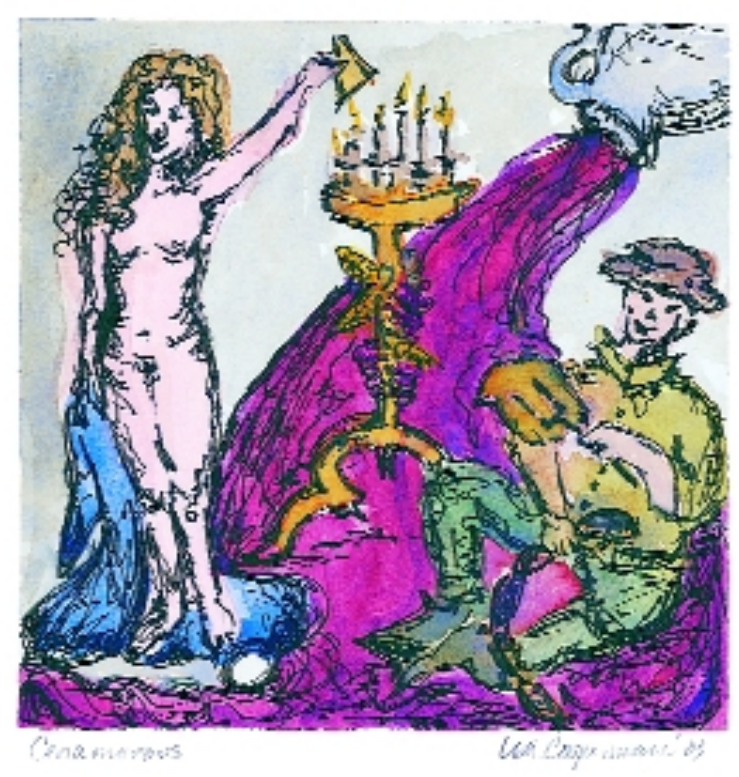

The Language of GaStronomy is paltry when compared to the rich, concise vocabulary employed by other disciplines. The paucity of good terminology becomes painfully apparent when analyzing cooking methods, flavors, and food habits of the past. The researcher must constantly explain in terms of differences from the present rather than being able to draw on a useful critical lexicon. Some disciplines - taxonomy, and the sciences in generalroutinely invent words whenever they discover a new species, element, or star. Why should the field of food studies be bereft of these invaluable aids to discourse? To this end, the following words have been devised as a starting point. Our hope is that some may come into general usage, or at least prompt other researchers to find better terms, so that the field of food studies might eventually have an expressive vocabulary of its own. $\odot$

adipatry: the tradition of using animal fat as the primary cooking medium. From Latin adeps, adipis, "fat," and patria, "fatherland."

albondiguillescent: a preference for small, dainty foods in meatball form. From the Spanish for "little meatballs."

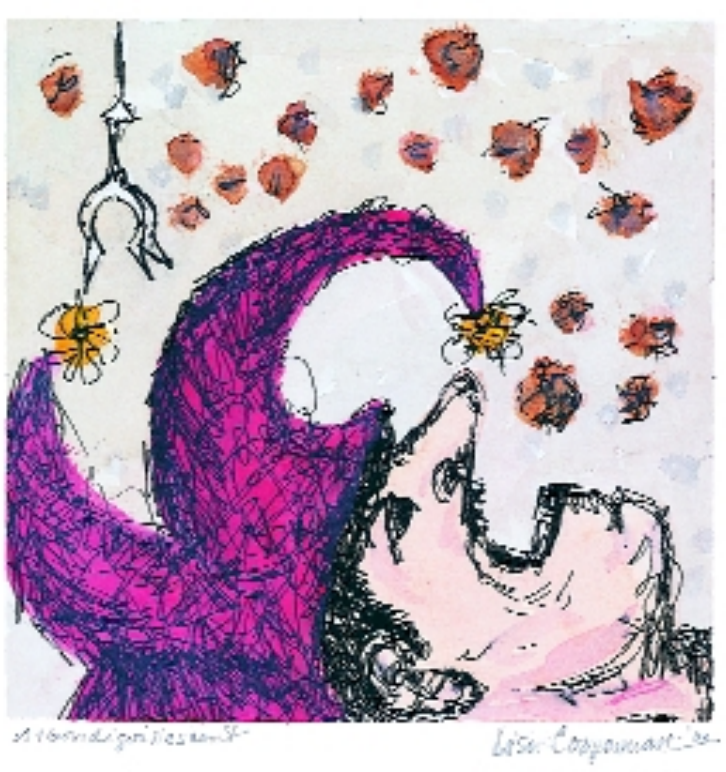

cenamorous: an intimate meal, often laden with aphrodisiacs, whose intention is to arouse feelings of passion. From Italian cena, "supper."

chromorexia: desire or hunger for colored foods. From Greek chrom, "color," and orexia, "hunger."

frixophobic: the fear of frying. Characteristic of medical advice from the sixteenth century onward.

monollaic: a meal cooked entirely in one pot, as with a hodge-podge or classic Spanish olla podrida, which translates literally as rotten pot or potpourri.

polyopsony: derived from Greek opson, things eaten with bread or as a condiment, and Latin opsonia, a broader term referring to banquet foods. Many cuisines present a main ingredient with a variety of sauces and flavorings that each diner can add at will. This presentation affords the diner a creative role in the ultimate flavor and texture of the dish, since many different condiments can be added to create layers of flavor. The term can be applied to a Southeast Asian meal that typically offers several standard condiments, or to a hamburger, for which the diner has a choice of ketchup, mustard, relish, etc. The antonym would be monopsony. 